Topics in Chemical \& Material Engineering (TCME) 1(1) (2018) 76-78

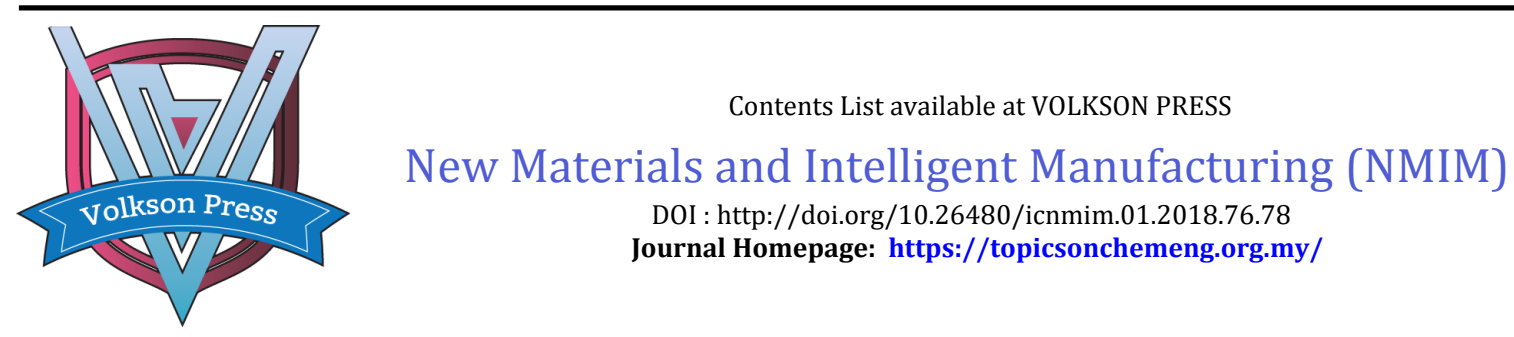

ISBN: 978-1-948012-12-6

\title{
A STUDY FOR COMPOUND RARE EARTH CHEMICAL TREATMENT LIQUID BASED ON BRASS SURFACE
}

\author{
Gan Shu-Kun, Liu Shuang*, Lv Xue-Fei * \\ College of Mechanical \& Electrical Engineering, Jilin Institute of Chemical Technology,45, Chengde Street, Jilin City, China. \\ *Corresponding Author Email: gsk@jlict.edu.cn
}

This is an open access article distributed under the Creative Commons Attribution License, which permits unrestricted use, distribution, and reproduction in any medium, provided the original work is properly cited

\section{ARTICLE DETAILS}

\section{Article History:}

Received 26 June 2018

Accepted 2 July 2018

Available online 1 August 2018

\section{ABSTRACT}

In this paper, the optimum technological conditions of brass composite rare earth chemical treatment liquid were obtained by orthogonal test. The process conditions for chemical degreasing, chemical polishing and pickling of brass pretreatment are given in the paper. The brass surface treated with different chemical treatment liquids was evaluated by nitric acid drop method and neutral salt spray test method. The morphology of the brass surface treated with the compound rare earth chemical treatment liquid was studied by electronic scanning electron microscope (SEM), comparing with the surface morphology of brass treated with the treatment solution containing rare earth yttrium salt in the optimal chemical treatment solution. The results show, the nitric acid drip time of brass treated with compound rare earth chemical treatment liquid is $22 \mathrm{~s}$. There is no obvious change in the surface of brass in the neutral salt spray experiment $14 \mathrm{~h}$. Greatly improves the corrosion resistance of the brass surface. The surface color of the composite rare earth chemical treatment liquid film layer is uniformly golden yellow, the film is smooth and dense, no defects exist.

\section{KEYWORDS}

Brass, Composite rare earth, Treatment solution, Corrosion resistance.

\section{INTRODUCTION}

Brass has good mechanical properties, thermoplasticity, easy cutting and easy welding, it is used to manufacture valves, pipes, air-conditioner internal and external machine connecting pipes, radiators, etc. However, in high humidity and corrosive media, severe corrosion can easily occur [1]. Lead to a significant reduction in the service life of brass parts. The surface passivation film-forming techniques is a cost-effective method for corrosion protection of brass surfaces. Rare earth salts have been widely used in recent years, the research work on the rare earth conversion film on the brass workpiece surface was limited to the preliminary research on the single rare earth passivation process and other aspects. This article will be obtained composite rare earth chemical treatment liquid formula by orthogonal test. Through the treatment of brass workpiece surface, the complex rare earth conversion film is formed on the surface and evaluate the corrosion resistance.

\section{TEST}

\subsection{Materials and Processes}

Material specimen is $\mathrm{H} 62$ brass (commercially available), is $\mathrm{Cu}-\mathrm{Zn}$ alloy. The main chemical composition (Wt\%):61.811\%Cu,35.662\%Zn, the rest is impurities. Sample size: $30 \mathrm{~mm} \times 10 \mathrm{~mm} \times 2 \mathrm{~mm}$, Top side hit $2 \mathrm{~mm}$ aperture for easy suspension. The processing flow: sandpaper polishing $\rightarrow$ distilled water flow washing $\rightarrow$ chemical degreasing $\rightarrow$ distilled water flow washing $\rightarrow$ chemical polishing $\rightarrow$ distilled water flow washing $\rightarrow$ pickling $\rightarrow$ distilled water flow washing $\rightarrow$ Rare earth passivation $\rightarrow$ distilled water flow washing $\rightarrow$ blow drying [2].

\subsection{Experiment Method}

Chemical soaking: All reagents are analytical grade, Composite rare earth optimal chemical treatment liquid process obtained by orthogonal test.

\subsubsection{Pre-processing}

a. Grinding and polishing: metallographic sandpaper grinding work surface to 2000 \# remove the original metal surface after washing and drying.

b. Chemical Degreasing: Dipping the dried sample into a chemical degreasing solution to remove oil, the main reagent components and processes are shown in Table 1 [3].

Table 1: Chemical Degreasing Parameters

\begin{tabular}{|lcccccc|}
\hline $\begin{array}{l}\text { Name } \\
(\text { Unit })\end{array}$ & $\begin{array}{c}\mathrm{NaOH} \\
\left(\mathrm{g} \cdot \mathrm{L}^{-1}\right)\end{array}$ & $\begin{array}{c}\mathrm{Na}_{3} \mathrm{CO}_{3} \\
\left(\mathrm{~g} \cdot \mathrm{L}^{-1}\right)\end{array}$ & $\begin{array}{c}\mathrm{Na}_{4} \mathrm{SiO}_{4} \\
\left(\mathrm{~g} \cdot \mathrm{L}^{-1}\right)\end{array}$ & $\begin{array}{c}\mathrm{Na}_{3} \mathrm{PO}_{4} \\
\left(\mathrm{~g} \cdot \mathrm{L}^{-1}\right)\end{array}$ & $\begin{array}{c}\text { Temperature } \\
\left({ }^{\circ} \mathrm{C}\right)\end{array}$ & $\begin{array}{c}\text { Time } \\
(\mathrm{min})\end{array}$ \\
\hline $\begin{array}{l}\text { Parameter } \\
\text { value }\end{array}$ & 30 & 70 & 30 & 10 & $80 \pm 5$ & $3 \pm 1$ \\
\hline
\end{tabular}

c. Chemical polishing: Put the sample into the chemical polishing solution, Multiple polishings in the same polishing time to give the sample a mirror finish. The main reagent components and processes are shown in Table 2 [4].

Table 2: Chemical Polishing Process Parameters

\begin{tabular}{|lllll|}
\hline $\begin{array}{l}\text { Name } \\
(\text { Unit })\end{array}$ & $\begin{array}{l}\mathrm{H}_{2} \mathrm{O}_{2} \\
\left(\mathrm{ml} \cdot \mathrm{L}^{-1}\right)\end{array}$ & $\begin{array}{l}\text { Surfactant } \\
\left(\mathrm{ml} \cdot \mathrm{L}^{-1}\right)\end{array}$ & $\begin{array}{l}\text { Temperature } \\
\left({ }^{\circ} \mathrm{C}\right)\end{array}$ & $\begin{array}{l}\text { Time } \\
(\mathrm{min})\end{array}$ \\
\hline $\begin{array}{l}\text { Parameter } \\
\text { value }\end{array}$ & 180 & $2-4$ & $37 \pm 2$ & $4 \pm 1$ \\
\hline
\end{tabular}

d. Pre-sulfuric acid wash: The polished and dried sample was immersed in a $10 \%$ sulfuric acid solution for activation to remove the brass surface oxide film. The process parameters are shown in Table 3 [5]. 
Table 3: Pickling Process Parameters

\begin{tabular}{|llll|}
\hline $\begin{array}{l}\text { Name } \\
\text { (Unit) }\end{array}$ & $\begin{array}{l}\mathrm{H}_{2} \mathrm{SO}_{4} \\
\left(\mathrm{ml} \cdot \mathrm{L}^{-1}\right)\end{array}$ & $\begin{array}{l}\text { Temperature } \\
\left({ }^{\circ} \mathrm{C}\right)\end{array}$ & $\begin{array}{l}\text { Time } \\
(\mathrm{min})\end{array}$ \\
\hline $\begin{array}{l}\text { Parameter } \\
\text { value }\end{array}$ & $; 0-150$ & Room temperature $i-10$ \\
\hline
\end{tabular}

\subsubsection{Composite rare earth chemical treatment liquid process}

Determine the initial process composition,Obtaining optimum process conditions through orthogonal test [5-6]. The ingredients are barium salts, barium salts, sodium molybdate, citric acid, sulphosalicylic acid, surfactants and parameters of temperature and time.

\subsection{Film Performance Test}

The evaluation criteria for film properties are as follows:

According to the optimal test table obtained from orthogonal test, Chemical treatment of pretreated samples, and evaluate the film obtained from each group of tests and give a score. The following standard [7].

a. Appearance color: The surface of the coated brass should have a rainbow color, membrane layer should be continuous and complete, non-absorbent cotton removable brown and dark yellow loose film.

b. Surface brightness: Coated brass should have a smooth surface and high brightness, no marble fog.

c. Nitric acid drip: Using 1:3 (volume ratio) 25\% nitric acid solution, drops the surface of brass on a rare earth conversion film obtained under different process conditions. Each selected 3 samples measured 5 times, make a note of when the first bubble was generated, and average the time [7-8].

d. According to the national standard GB/T3826-1999, This experiment used $\mathrm{NaCl}$ solution in RK-60 salt spray test chamber, four consecutive samples of passivated film were selected for cleaning and drying, followed by continuous spray test, and observe the changes of the surface of each sample at regular intervals [9-10].

\section{RESULT}

\subsection{Optimal Process}

The above three film layer scores were scored on a 3:3:4 scale in each group of film layers. The composite rare earth chemical treatment solution by orthogonal experimental is shown in Table 4 .

Table 4: Chemical Treatment Solution

\begin{tabular}{|ll|}
\hline Factor & Parameter \\
\hline $\mathrm{La}_{3}(\mathrm{NO})_{3}(\mathrm{~g} / \mathrm{L})$ & $4 \pm 0.5$ \\
$\mathrm{Ce}_{3}(\mathrm{NO})_{3}(\mathrm{~g} / \mathrm{L})$ & $4 \pm 0.5$ \\
Benzotriazole(BTA) (g/L) & $14 \pm 0.5$ \\
Citric acid( g/L) & $3 \pm 0.5$ \\
Sodium molybdate(g/L) & $14 \pm 0.5$ \\
Sulfosalicylic acid(g/L) & $10 \pm 0.5$ \\
Surfactant $(\mathrm{g} / \mathrm{L})$ & 0.1 \\
Temperature $\left({ }^{\circ} \mathrm{C}\right)$ & $50 \pm 0.5$ \\
Time (min) & 5 \\
\hline
\end{tabular}

\subsection{Resistance Test}

Testing of the corrosion resistance of the film obtained by adding a rare earth salt, a single rare earth salt (niobium nitrate), and without adding any rare earth salt passivation solution by nitric acid dripping test. Shown in Figure 1.

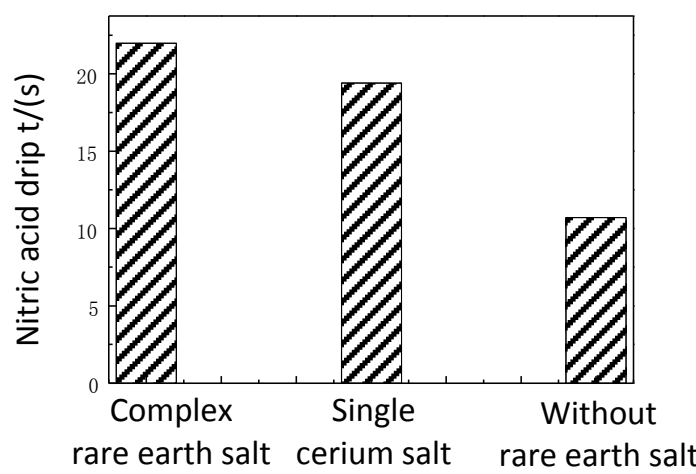

Figure 1: Corrosion Resistance of Samples Treated with Different Treatment Fluids

It can be seen from Figure 1. The resistance to nitric acid was only $10.7 \mathrm{~S}$ without adding any rare earth salt, the worst corrosion resistance. The anti-corrosion time of adding cerium nitrate film is 18.4s. La (Ce) composite film resistant to nitric acid for up to 22 s, it shows that the film has the best corrosion resistance.

The result of the neutral salt spray test is shown in Table 5. The table shows corrosion resistance of brass substrate surface treated with compound rare earth chemical treatment liquid is significantly improved. The single rare earth cerium salt film is discolored at the edges after 12 hours of continuous spraying. However, after the composite rare-earth chemical treatment solution was treated in the salt fog box, a small number of spots that were hardly visible to the naked eye appeared on the surface after 15 hours, and still very bright. At this time, a single rare earth salt film has been discolored, brown spots, lost gloss and other phenomena. Therefore, the composite rare-earth composite film exhibits superior corrosion resistance in neutral salt spray test.

Table 5: Neutral Salt Spray Test Results

\begin{tabular}{|lll|}
\hline Before the test & Single cerium salt & Complex rare earth salt \\
time & $\begin{array}{l}\text { Bright surface with } \\
\text { tiny fine lines }\end{array}$ & $\begin{array}{l}\text { Yellow dense, uniform } \\
\text { color, bright surface }\end{array}$ \\
\hline $10 \mathrm{~h}$ & No change & No change, uniform light \\
$12 \mathrm{~h}$ & $\begin{array}{l}\text { Slight discoloration, } \\
\text { surface integrity }\end{array}$ & No change, still bright \\
& $\begin{array}{l}\text { Discoloration around } \\
\text { the edges }\end{array}$ & No change, still bright \\
$14 \mathrm{~h}$ & $\begin{array}{l}\text { Fog marks appear } \\
\text { locally and the surface } \\
\text { is bright }\end{array}$ & $\begin{array}{l}\text { No significant changes, } \\
\text { still uniform color }\end{array}$ \\
$15 \mathrm{~h}$ & $\begin{array}{l}2 / 3 \text { surface is brown } \\
\text { spots, uneven and dull } \\
\text { color }\end{array}$ & $\begin{array}{l}\text { A very small amount of } \\
\text { visible spots, bright } \\
\text { surface }\end{array}$ \\
\hline
\end{tabular}

\subsection{Characterization of Film Properties}

Using JSM-6490LV scanning electron microscope to characterize the morphology of conversion coatings obtained from different chemical treatment fluid formulations, see $[9,10]$. Figure 2 shows the comparison of the morphology of the film after treatment with different treatment liquids 
at a magnification of 200 times in the scanning electron microscope. According to the picture, single rare earth yttrium salt sample surface is light in color, there are pit defects and cracks that are not allowed, exposed body. The composite rare-earth chemical treatment liquid film surface uniform color golden yellow, no defects exist.

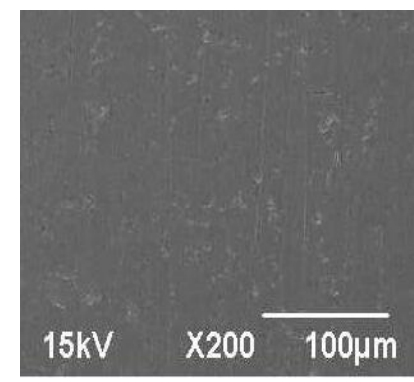

a. Single Cerium Salt

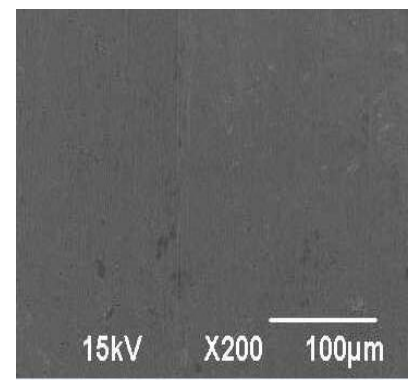

b. Composite Rare Earth Salt
Figure 2: SEM Comparison of Different Layers

\section{CONCLUSION}

The optimum process for chemical treatment of composite rare earths on brass surface is obtained by orthogonal test: $\mathrm{La}(\mathrm{NO})_{3} \cdot 6 \mathrm{H}_{2} \mathrm{O}-4 \mathrm{~g} / \mathrm{L}$, $\mathrm{Ce}(\mathrm{NO})_{3} \cdot 6 \mathrm{H}_{2} \mathrm{O}-4 \mathrm{~g} / \mathrm{L}, \mathrm{BTA}-14 \mathrm{~g} / \mathrm{L}, \mathrm{Na}_{2} \mathrm{MoO}_{4} \cdot 2 \mathrm{H}_{2} \mathrm{O}-3 \mathrm{~g} / \mathrm{L}_{,} \mathrm{C}_{6} \mathrm{H}_{8} \mathrm{O}_{7} \cdot \mathrm{H}_{2} \mathrm{O}-14 \mathrm{~g} / \mathrm{L}$, $\mathrm{C}_{7} \mathrm{H}_{7} \mathrm{O}_{6} \mathrm{~S} \cdot 2 \mathrm{H}_{2} \mathrm{O}-10 \mathrm{~g} / \mathrm{L}, \mathrm{C}_{18} \mathrm{H}_{29} \mathrm{NaO}_{3} \mathrm{~S}-0.1 \mathrm{~g} / \mathrm{L}$, temperature $50{ }^{\circ} \mathrm{C}$, time $5 \mathrm{~min}$.

The corrosion resistance of comparative layers under different process conditions is test using nitric acid dripping test and neutral salt spray test. The results show that the rare earth composite rare earth conversion coating can significantly improve the corrosion resistance of the brass surface, and the corrosion resistance is the strongest.

Scanning electron microscopy was used to characterize the morphology of each layer. The results show that compared to a single rare earth salt layer, the composite rare earth conversion film is more uniform and dense. Its strong bond with the substrate effectively protects the surface of the copper alloy from corrosion.

\section{REFERENCES}

[1] Zhenggui, L., Yijiang, W. 2005. Research Progress of Copper Corrosion and Protection. Journal of Wuhan Institute of Chemical Technology, 27 (2),17-20.
[2] Xuefei, L., Shuying, L. 2014. Role of lanthanum and benzotriazole in the passivation of brass. Material Protection, (10),45-47+8.

[3] Guichang, L. 2013. Preparation and Corrosion Behavior of Corrosion Resistant Material on Gas Condenser Surface. Dalian University of Technology.

[4] Jingli, F. 2005. Chemical Polishing of Metals Part 3 Chemical Polishing of Copper and Copper Alloy Parts. Plating and Finishing, (10), 41-46.

[5] Shukun, G., Xuefei, L.Y. 2008. Study on Properties of Lanthanum Nitrate Passivation Film on Copper Alloy. Journal of Materials Protection, (08), 3537+79-80.

[6] Xuefei, L. 2006. Preparation and properties of H62 copper alloy rare earth passivation film[D]. Dalian University of Technology.

[7] Wei, C., Songhua, Z., Jidan, L. 2014. Study on Environmental Protection Passivation Process of Copper Surface. Aerospace Manufacturing Technology, (01),30-33.

[8] Liangwei, F. 2012. Preparation and properties of composite film on copper alloy surface. Shanghai Jiaotong University.

[9] Liangwei, F. 2013. Corrosion Inhibition of Cu-Zn-Ni Copper Alloy in $3.5 \% \mathrm{NaCl}$ Solution by Barium Salt Type Corrosion Inhibitor. Corrosion and Protection, (01), 36-41.

[10] Wei, Z. 2012. Film-forming process and corrosion resistance of a novel chromium-free conversion coating on red copper surface. Hefei University of Technology.

\section{ABOUT THE AUTHORS}

Fund: "13th Five-Year Plan" Science and technology Task of Jilin Provincial Committee of Education (JJKH20170218KJ); Major science and technology Task of Jilin Institute of Chemical Technology (A1600040)

Author: Gan Shu-kun (1973-), Male, from Dehui, Jinlin , Master, Associate professor, Research focus: Power machinery, thermal energy and power engineering ,surface engineering of material.

* Corresponding author: Lv Xue-fei (1975-), Female, from Dehui , Jinlin , Master, Associate professor, Research focus: surface engineering of material, thermal energy and power engineering.

** Liu Shuang, Postgraduate, Jilin Institute of Chemical Technology. 